\title{
BMJ Open Anaemia among primary care patients with type 2 diabetes mellitus (T2DM) and chronic kidney disease (CKD): a multicentred cross-sectional study
}

\author{
Iliza Idris, ${ }^{1}$ Hizlinda Tohid, ${ }^{2}$ Noor Azimah Muhammad, ${ }^{2}$ Mohd Radzniwan A Rashid, ${ }^{3}$
} Azainorsuzila Mohd Ahad, ${ }^{4}$ Norsiah Ali, ${ }^{5}$ Naemah Sharifuddin, ${ }^{6}$ Junita Harizon Aris ${ }^{7}$

To cite: Idris I, Tohid $\mathrm{H}$, Muhammad NA, et al. Anaemia among primary care patients with type 2 diabetes mellitus (T2DM) and chronic kidney disease (CKD): a multicentred cross-sectional study. BMJ Open 2018;8:e025125. doi:10.1136/ bmjopen-2018-025125

- Prepublication history for this paper is available online. To view these files, please visit the journal online (http://dx.doi. org/10.1136/bmjopen-2018025125).

Received 20 August 2018 Revised 25 October 2018 Accepted 16 November 2018

Check for updates

(C) Author(s) (or their employer(s)) 2018. Re-use permitted under CC BY-NC. No commercial re-use. See rights and permissions. Published by BMJ.

For numbered affiliations see end of article.

Correspondence to

Dr Hizlinda Tohid;

hizlinda2202@gmail.com

\section{ABSTRACT}

Objectives This study aimed to determine the prevalence of anaemia among patients with type 2 diabetes mellitus (T2DM) and chronic kidney disease (CKD) at primary care settings and its associated factors.

Design, setting and participants This cross-sectional study involved 808 adult patients with T2DM and CKD who were recruited via systematic sampling from 20 public primary care clinics in Peninsular Malaysia. Their sociodemographic, clinical and biomedical profiles were collected through interviews, examination of medical records and blood testing.

Results The prevalence of anaemia was $31.7 \%$ (256/808). The anaemia was mainly mild (61.5\%) and normocytic normochromic (58.7\%). About $88.7 \%$ of the patients with anaemia were not known to have anaemia prior to the study. Among 36 patients with documented history of anaemia, $80.6 \%$ were still anaemic, and only a half received iron therapy. Multivariate regression analysis showed that women (adjusted odd ratio (AOR): 1.57, $95 \% \mathrm{Cl}: 1.12$ to $2.21, \mathrm{p}=0.009)$ and those with older age (AOR: $1.04,95 \% \mathrm{Cl}: 1.01$ to $1.06, \mathrm{p}<0.001$ ), CKD stage $3 \mathrm{a}$ (AOR: $2.47 ; 95 \% \mathrm{Cl}: 1.25$ to $4.87, \mathrm{p}=0.009$ ), CKD stage $3 \mathrm{~b}$ (A0R: 4.36; 95\% Cl: 2.14 to $8.85, \mathrm{p}<0.001$ ), CKD stage 4 (AOR: $10.12 ; 95 \% \mathrm{Cl}: 4.36$ to $23.47, \mathrm{p}<0.001$ ), CKD stage 5 (AOR: 10.80; 95\% Cl: 3.32 to $35.11, p<0.001$ ) and foot complication (AOR 3.12, 95\% Cl: 1.51 to $6.46, p=0.002$ ) were more likely to have anaemia. Having higher body mass index (AOR 0.95, 95\% Cl: 0.92 to $0.99, \mathrm{p}=0.012$ ) and higher diastolic blood pressure (AOR 0.97, 95\% Cl: 0.95 to $0.99, p<0.001$ ) were associated with lower odds to have anaemia.

Conclusion Anaemia among patients with T2DM and CKD in primary care was common, and the majority was unrecognised. Inadequate treatment of anaemia was also prevalent. Therefore, screening of anaemia should be incorporated into the routine assessment of diabetic complications particularly for those with significant associated factors. It is hoped that such strategy could lead to early treatment and hence improve their overall care. Trial registration number NMRR-15-660-24324.

\section{INTRODUCTION}

Chronic kidney disease (CKD) is common among patients with type 2 diabetes mellitus
Strengths and limitations of this study

- This was the first nationwide study to examine the prevalence of anaemia among patients with type 2 diabetes mellitus (T2DM) and chronic kidney disease (CKD) involving a large sample from multicentres in Malaysian primary care setting.

- The findings help to identify those who require simple anaemia screening using full blood count and this potentially cost-saving approach of screening may improve the care of such patients.

- The findings could also provide a groundwork for future studies as previous studies on anaemia among patients with T2DM and CKD are still limited.

- Unfortunately in this study, the actual aetiology of the anaemia was not determined thus the anaemia may be caused by causes other than renal anaemia.

- Since this study did not include patients from the private primary care clinics and those in the east of Malaysia (Sabah and Sarawak), the prevalence of anaemia may be underestimated.

(T2DM). It is defined when there is an irreversible loss of kidney function for at least 3 months. ${ }^{1}$ The estimated glomerular filtration rate (eGFR) and evidence of kidney damage have been used to diagnose CKD, which can be divided into five stages based on the National Kidney Foundation-Kidney Disease Outcomes Quality Initiative staging. ${ }^{1}$ The estimated prevalence of diabetic nephropathy worldwide ranges between $26 \%$ and $58 \% \cdot{ }^{2-10}$ However, the prevalence appears lower in Malaysia as it ranges between $7.8 \%$ and $34.9 \%{ }^{11-15}$ This wide range of prevalence may be due to difference in study settings and definition used for diabetic nephropathy. Nevertheless, data from the National Diabetes Registry Malaysia in 2012 involving 657839 registered patients with T2DM from government health facilities including hospitals and primary care clinics showed a prevalence of $7.8 \%$. $^{14}$ 
CKD has been associated with anaemia, cardiovascular disease, bone metabolism abnormalities, metabolic acidosis and malnourishments. Among these, renal anaemia has been increasingly studied over the past few years due to high all-cause mortality and cardiovascular morbidity associated with renal anaemia, as well as availability of erythropoiesis stimulating agents (ESA) for treating renal anaemia. ${ }^{16}$ In addition, anaemia has also been found to be a significant independent factor for progression of nephropathy to end stage renal failure among patients with T2DM. ${ }^{18}$ Overall, renal anaemia carries significant burden to the sufferers as well as the healthcare system that bears the cost of care for patients with T2DM and CKD.

According to the Kidney Disease: Improving Global Outcomes (KDIGO) Anemia Work Group, anaemia in CKD is when haemoglobin $(\mathrm{Hb})$ level $<13 \mathrm{~g} / \mathrm{dL}$ for men and $<12 \mathrm{~g} / \mathrm{dL}$ for women. ${ }^{19}$ It is caused by multiple pathophysiological mechanisms which include erythropoietin deficiency, nutritional deficiencies (iron, folate and $\mathrm{B}_{19}$ ), pro-inflammatory condition and poor response to erythropoietin that results in erythropoiesis suppression. ${ }^{1620}$ Prevalence of anaemia has been found to be higher among CKD patients with T2DM compared with those without T2DM. ${ }^{41}$ Among patients with T2DM, the prevalence of anaemia increases as their renal function deteriorates. ${ }^{4-79} 22$ In the UK, a population-based study involving 234 patients with T2DM showed 5\%, 16\%, 23\% and $46 \%$ of those with CKD stage 1, 2, 3 and 4/5, respectively, had anaemia. ${ }^{22}$

Factors that were shown to be associated with anaemia among patients with T2DM include older age, worsening renal function (ie, lower eGFR, higher albuminuria and raised urine-albumin creatinine ratio), cardiovascular disease (stroke or ischaemic heart disease), peripheral vascular disease, lower weight or body mass index (BMI), lower diastolic blood pressure (DBP), longer duration of T2DM and not using ACE inhibitor. ${ }^{2} 492324$ However, there are inconsistent findings with regard to the association between gender and anaemia among patients with T2DM and CKD. Anaemia was significantly associated with women in studies done in Australia ${ }^{2}$ and the $\mathrm{UK}^{4}$ but a study in Hong Kong found its significant association with men. ${ }^{9}$

Currently, screening for anaemia among these patients at the public primary care settings in Malaysia is not the standard of practice. Full blood count (FBC) would only be performed if clinically indicated. Due to financial limitation, asymptomatic patients and those without overt bleeding problems and constitutional or alarming symptoms would be normally prescribed with iron supplements. If there is no improvement with this therapy, they will then be subjected to further investigations to ascertain the aetiology of the anaemia. To our knowledge, there is no published national study to determine the prevalence of anaemia among patients with T2DM and CKD in Malaysia. Thus, the burden of this problem remains unknown. Therefore, this study aimed to determine the prevalence of anaemia among patients with T2DM and CKD who received care from the public primary care clinics in Peninsular Malaysia. Its associated factors were also examined as the findings could help the healthcare providers in identifying patients at higher risk for anaemia, thus screening of anaemia could be targeted to these patients.

\section{METHODS}

This was a cross-sectional observational study conducted at 20 government primary care clinics in Peninsular Malaysia which have resident Family Medicine Specialists. Fifteen clinics were selected using simple random sampling but five clinics were purposely chosen because they were managed by the researchers of this study. On average, there were 1000-3000 patients with T2DM registered at these clinics who stayed within $30 \mathrm{~km}$ radius from the respective clinics.

\section{Study participants}

Through systematic sampling, every third patient who attended for a follow-up visit during the data collection period (October to December 2015) was screened for their eligibility to be included in this study. The inclusion criteria were patients with T2DM aged 18 years old or more who had established CKD stage 1 to 5 and were able to understand either Malay or English language. Patients who were pregnant or had a recent delivery within previous 3 months or those with psychiatric illness or known anaemia secondary to any blood disorder such as thalassaemia were excluded from this study. Eligible patients were invited to participate in the study by research assistants in the respective clinics. A maximum of eight patients recruited daily from each clinic and the recruitment process stopped once 50 patients were sampled. The minimum targeted sample size for this study was 1000 with a design effect of 2.0 which was sufficed to give $4 \%$ precision from the expected prevalence of anaemia of $30 \%$. All patients who agreed to participate were interviewed for their socio-demographic profiles and medical histories by the respective research assistants. Subsequently, their clinical and biomedical profiles were collected from their medical records. Blood taking for renal profiles or FBC was done if there was no recent result within the past 6 months. Patients with anaemia found through this study were treated according to the recommended practice and referred to the nephrologist when indicated.

\section{Patient and public involvement}

Patients with T2DM and CKD from each clinics were not involved in the design of the study and the recruitment of the participants. The results of the blood test were immediately informed to the study participants and appropriate management based on the results was carried out by the attending physician. Since this was a cross-sectional study, their involvement was only during their clinic visit when they completed the self-administered questionnaire. 


\section{Definition of variables}

Anaemia was defined based on KDIGO clinical practice guideline for anaemia in CKD when $\mathrm{Hb}<13.0 \mathrm{~g} /$ $\mathrm{dL}$ in men and $<12.0 \mathrm{~g} / \mathrm{dL}$ in women (KDIGO, 2012). Using eGFR and evidence of kidney damage (eg, microalbuminuria or proteinuria), CKD was classified into: stage 1: eGFR $\geq 90 \mathrm{~mL} / \mathrm{min} / 1.73 \mathrm{~m}^{2}$ with albuminuria or proteinuria, stage 2: eGFR $60-89 \mathrm{~mL} / \mathrm{min} / 1.73 \mathrm{~m}^{2}$ with albuminuria or proteinuria, stage 3a: eGFR $45-59 \mathrm{~mL} /$ $\min / 1.73 \mathrm{~m}^{2}$, stage $3 \mathrm{~b}:$ eGFR $30-44 \mathrm{~mL} / \mathrm{min} / 1.73 \mathrm{~m}^{2}$, stage 4: eGFR $15-29 \mathrm{~mL} / \mathrm{min} / 1.73 \mathrm{~m}^{2}$ and stage 5 : eGFR $<15 \mathrm{~mL} / \mathrm{min} / 1.73 \mathrm{~m}^{2}$. Presence of comorbidities and complications were determined through history taking or documentation in the medical records.

\section{Statistical analysis}

The statistical analysis was carried out using IBM SPSS Statistics V.22. All statistical analyses were performed at the 5\% significance level. Findings were presented descriptively using mean (SD) and median (IQR) for normally and non-normally distributed continuous variables, respectively, while results of categorical variables were presented as frequencies (n) and percentages (\%). Multiple logistic regression analysis with forward stepwise method was used to identify the associated factors of anaemia among patients with T2DM and CKD. Interactions between predictor variables and model fitness were also assessed.

\section{RESULTS}

The mean (SD) age of the participants was 60.5 (9.5) years old (table 1$)$. The majority of the participants were Malays $(75.2 \%)$. Men $(56.2 \%)$ were slightly more than women $(43.8 \%)$. The median (IQR) for duration of diabetes and CKD were 7.0 (8.0) years and 2.0 (3.0) years, respectively, with median (IQR) of eGFR was 55.0 (34.0) $\mathrm{ml} / \mathrm{min} / 1.73 \mathrm{~m}^{2}$. More than two-thirds of the patients were on either ACE inhibitors or angiotensin receptor blockade $(72.2 \%)$. There was no significant difference in the presence of anaemia between those who received this treatment and those without $(\mathrm{p}=0.961)$. The most common comorbidities were hypertension $(88.5 \%)$ and dyslipidaemia $(82.7 \%$ ) (table 2).

The prevalence of anaemia among patients with T2DM and CKD was $31.7 \%$ (256/808) with most of the anaemic patients having mild anaemia $(61.5 \%, 166 / 256)$ and morphological classification of normocytic normochromic anaemia $(58.7 \%, 148 / 252)$. The mean (SD) $\mathrm{Hb}$ of all patients was $13.18(1.81) \mathrm{g} / \mathrm{dL}$.

The prevalence of anaemia among patients with T2DM and CKD 1, 2, 3a, 3b, 4 and 5 were $12.7 \%, 19.1 \%, 29.6 \%$, $46.4 \%, 68.3 \%$ and $70.0 \%$, respectively (table 3 ). Table 3 also shows that more patients had $\mathrm{Hb}<10 \mathrm{~g} / \mathrm{dL}$ as stages of CKD increased, particularly those with CKD stage 4 and 5. Normocytic hypochromic anaemia also appeared to be more common at advanced stages of CKD, whereas microcytic hypochromic anaemia was more common at earlier stages of CKD (table 3).

Majority of the patients with anaemia $(88.7 \%, 227 / 256)$ had unrecognised anaemia as they were not known to have anaemia prior to this study (table 1). Among 36 patients who had documented history of anaemia prior to the study, $80.6 \%(29 / 36)$ were still anaemic. Only about a half $(15 / 29)$ of these patients received iron therapy.

Table 4 showed the results of the multivariate regression analysis. Women (adjusted odd ratio (AOR): 1.56, 95\% CI: 1.12 to 2.21, $\mathrm{p}=0.009$ ) and those with older age (AOR: $1.04,95 \%$ CI: 1.01 to $1.06, \mathrm{p}<0.001$ ), CKD stage $3 \mathrm{a}$ (AOR: $2.47 ; 95 \%$ CI: 1.25 to $4.87, \mathrm{p}=0.009$ ), CKD stage $3 \mathrm{~b}$ (AOR: 4.36 ; $95 \%$ CI: 2.14 to 8.85 , $\mathrm{p}<0.001$ ), CKD stage 4 (AOR: 10.12; 95\% CI: 4.36 to 23.47, p<0.001), CKD stage 5 (AOR: 10.80; 95\% CI: 3.32 to 35.11, $\mathrm{p}<0.001$ ) and foot complication (AOR 3.12, 95\% CI: 1.51 to $6.46, \mathrm{p}=0.002$ ) were more likely to have anaemia. Having higher BMI (AOR 0.95, 95\% CI: 0.92 to $0.99, p=0.012$ ) and higher DBP (AOR 0.97, 95\% CI: 0.95 to 0.99 , $\mathrm{p}<0.001$ ) were associated with lower odds to have anaemia.

\section{DISCUSSION}

Overall, patients with T2DM and CKD in this study were slightly different than general patients with diabetes from the national studies in Malaysia. ${ }^{12} 131525$ Unlike our study which recruited patients from primary care clinics only, the previous Malaysian studies mostly include patients from the tertiary centres. Therefore the study populations were different in terms of gender, ethnicity, duration of diabetes and severity of disease. ${ }^{12} 1425$ Men were slightly more than women in our study, whereas women were predominant in the other national studies. The Malays appear to be substantially more represented and this finding is consistent with Chew et al. ${ }^{13}$ In this latter study, poor renal function was found to be more common among the Malays than the other ethnics. ${ }^{13}$ Our participants also had longer duration of diabetes than the general patients with diabetes. This is expected since nephropathy is more common as diabetes progresses and substantial proportion of patients with T2DM in Malaysia are on long term follow-up at primary care clinics.

In this study, the prevalence of anaemia among patients with T2DM and CKD at primary care clinics was $31.7 \%$. This prevalence was lower than another local study (39.4\%) by Thambiah et al which was done among 165 patients with T2DM and CKD at the endocrine clinic of a tertiary hospital in Putrajaya, the federal administrative centre of Malaysia. ${ }^{26}$ The difference in the prevalence may be because of the difference in the study sites. Higher prevalence of anaemia was also found in studies done at tertiary centres worldwide that ranged between 39.0\% and 58.0\%. ${ }^{4579}$ Nevertheless, the prevalence of anaemia in the current study was almost similar with a study done in 11 European countries (34.0\%) involving 1205 patients with T2DM and CKD who were recruited from primary, secondary and tertiary settings. ${ }^{8}$ This European 
Table 1 Bivariate analysis of the participants' demographic and clinical characteristics with anaemia status

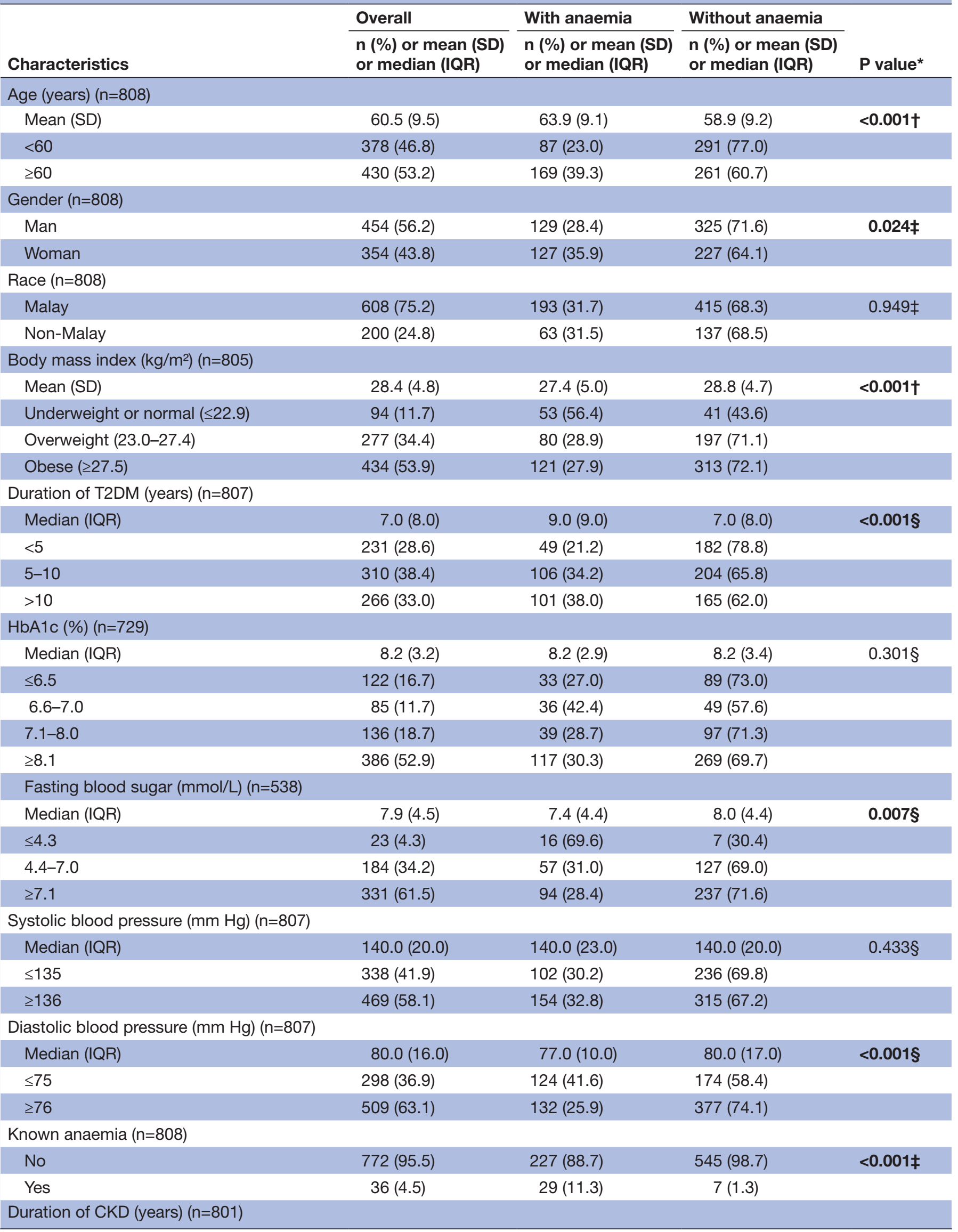


Table 1 Continued

\begin{tabular}{|c|c|c|c|c|}
\hline & Overall & With anaemia & Without anaemia & \\
\hline Characteristics & $\begin{array}{l}\text { n (\%) or mean (SD) } \\
\text { or median (IQR) }\end{array}$ & $\begin{array}{l}\mathrm{n}(\%) \text { or mean (SD) } \\
\text { or median (IQR) }\end{array}$ & $\begin{array}{l}\mathrm{n}(\%) \text { or mean (SD) } \\
\text { or median (IQR) }\end{array}$ & P value* \\
\hline \multicolumn{5}{|c|}{ Treated with ACE-i or ARB } \\
\hline No & $225(27.8)$ & 71 (31.6) & $154(68.4)$ & $0.961 \ddagger$ \\
\hline
\end{tabular}

*Significance $p<0.05$ (values in bold).

†Independent t-test.

$\neq X^{2}$ test.

§Mann-Whitney test.

ACE-i, ACE inhibitor; ARB, angiotensin II receptor blocker; CKD, chronic kidney disease; HbA1c, haemoglobin A1c; T2DM: type 2 diabetes mellitus.

study used the same definition of anaemia as our study. ${ }^{8}$ Two other studies done among patients with diabetic nephropathy in the $\mathrm{UK}^{6}$ and Japan ${ }^{10}$ demonstrated even lower prevalence of anaemia compared with others in which both studies showed a prevalence of $26.0 \%$.

Most of the patients with anaemia in this study had normocytic normochromic anaemia especially those at advanced stages of CKD. This morphological classification of anaemia has been shown to be common not just among patients with $\mathrm{CKD}^{27}$ in general but those with diabetic nephropathy ${ }^{926}$ as well. This is due to impaired renal erythropoietin production and response to erythropoietin. ${ }^{28}$ Nevertheless, microcytic hypochromic anaemia was quite prevalent particularly at earlier stages of CKD (CKD stage 1-3). Since thalassaemia can cause this type of anaemia and is common in Southeast Asia like Malaysia, it is important to differentiate between patients with this illness and iron deficiency who require iron therapy. ${ }^{29}$ Furthermore, patients with diabetes and CKD may have functional iron deficiency which requires replenishment of iron store before they could have definitive treatment of persistent renal anaemia with ESA. ${ }^{19} 28$ The iron therapy can be initiated even at primary care setting and since most patients with anaemia had mild anaemia, as shown by the current study and Thambiah $e t a l,{ }^{26}$ treatment with oral therapy may be suffice.

The current study also highlights a high prevalence of unrecognised anaemia among patients with T2DM and CKD whereby $88.7 \%$ of the patients with anaemia were not diagnosed to have anaemia prior to this study. This prevalence of unrecognised anaemia is substantially higher than those in the western countries, which was less than $25 \% .^{22}{ }^{30}$ The finding of this current study suggests inadequate screening to detect anaemia among patients with T2DM and CKD in Malaysian government primary care clinics. At present, screening for anaemia is not regularly practised, and there is a need to review our management. In addition, $80.6 \%$ of the participants with previous history of anaemia were still anaemic at the time of the study whereby $51.7 \%$ of them received iron therapy but unable to restore normal level of $\mathrm{Hb}$. About $48.3 \%$ of them were untreated. These findings indicate inadequate treatment of anaemia as similarly shown by Stevens et al which found only $22 \%$ of their known patients with anaemia treated with ESA or iron therapy. ${ }^{8}$ In this current study, more patients with CKD stage 4 and 5 had $\mathrm{Hb}$ of less $10 \mathrm{~g} / \mathrm{dL}$, which is when ESA treatment is indicated. Nevertheless, iron therapy should be initiated at primary care clinic to replenish their iron stores before referring them to nephrologists for ESA treatment. ${ }^{1928}$ This undetected, uninvestigated and undertreated anaemia is worrisome since it may worsen their renal function and causes adverse cardiovascular outcomes. ${ }^{28}$ Having a system to ensure screening of anaemia among at-risk patients will not produce favourable outcomes if anaemia is still not being properly managed. Since undertreated anaemia could be caused by many factors which include inadequate access to laboratory facilities, inadequate knowledge among doctors, patients' non-compliance, and cost of investigations and treatment, managing anaemia in patients with T2DM and CKD at primary health clinics is indeed challenging. Thus, further studies are required to confirm the actual causes of inadequate treatment of anaemia at primary care so that areas for improvement can be identified.

The mean $\mathrm{Hb}$ level of patients with T2DM and CKD in this study was almost similar with patients with diabetic nephropathy in Japan and European countries which was around $13 \mathrm{~g} / \mathrm{dL}{ }^{810}$ Hence, screening for all patients with diabetes with CKD may not be cost effective. Nevertheless, this study highlights the associated factors that may alert the treating doctors of those who require screening for anaemia. These factors include increasing age, female gender, CKD stage 3 and above, presence of foot complication, lower BMI and lower DBP. Similarly, previous studies have shown significant associations of anaemia with older age, ${ }^{92}$ female gender, ${ }^{4}$ lower BMI and $\mathrm{DBP}^{7}$ as well as higher stage of CKD. ${ }^{49}$ A study done at a nephrology clinic in Greece by Loutradis $e t$ al also showed that anaemia was more prevalent among patients with diabetes and CKD stage 3 compared with the non-diabetic with equivalent CKD stage. ${ }^{31}$ These findings were in line with the 
Table 2 Bivariate analysis of the participants' comorbidities and complications with anaemia status

\begin{tabular}{|c|c|c|c|c|c|c|c|}
\hline \multirow[b]{2}{*}{ Comorbidities and complications* } & \multicolumn{2}{|c|}{ All $(n=808)$} & \multicolumn{2}{|c|}{$\begin{array}{l}\text { With anaemia } \\
(n=256)\end{array}$} & \multicolumn{2}{|c|}{$\begin{array}{l}\text { Without anaemia } \\
(n=552)\end{array}$} & \multirow[b]{2}{*}{$P$ value } \\
\hline & $\mathbf{N}$ & $\%$ & $n$ & $\%$ & $\mathbf{n}$ & $\%$ & \\
\hline Hypertension & 715 & 88.5 & 232 & 90.6 & 483 & 87.5 & $0.195 \ddagger$ \\
\hline Dyslipidaemia & 668 & 82.7 & 205 & 80.1 & 463 & 83.9 & $0.184 \ddagger$ \\
\hline Ischaemic heart disease & 83 & 10.3 & 37 & 14.3 & 46 & 8.3 & $0.008 \ddagger$ \\
\hline Heart failure & 22 & 2.7 & 13 & 5.1 & 9 & 1.6 & $0.005 \ddagger$ \\
\hline Myocardial infarction & 11 & 1.4 & 5 & 2.0 & 6 & 1.1 & $0.508 \S$ \\
\hline Angina & 9 & 1.1 & 4 & 1.6 & 5 & 0.9 & $0.640 \S$ \\
\hline Cerebrovascular accident & 36 & 4.5 & 18 & 7.0 & 18 & 3.3 & $0.016 \ddagger$ \\
\hline Peripheral vascular disease & 5 & 0.6 & 1 & 0.4 & 4 & 0.7 & $0.935 \S$ \\
\hline \multicolumn{8}{|l|}{ Chronic kidney disease } \\
\hline Stage 1 & 102 & 12.6 & 13 & 5.1 & 89 & 16.1 & $<0.001 \ddagger$ \\
\hline Stage 2 & 230 & 28.5 & 44 & 17.2 & 186 & 33.7 & \\
\hline Stage 3ף & 240 & 29.7 & 71 & 27.7 & 169 & 30.6 & \\
\hline Stage $3^{\star \star}$ & 153 & 18.9 & 71 & 27.7 & 82 & 14.9 & \\
\hline Stage 4 & 63 & 7.8 & 43 & 16.8 & 20 & 3.6 & \\
\hline Stage 5 & 20 & 2.5 & 14 & 5.5 & 6 & 1.1 & \\
\hline Retinopathy & 151 & 18.7 & 64 & 25.0 & 87 & 15.8 & $0.002 \ddagger$ \\
\hline Neuropathy & 119 & 14.7 & 41 & 16.0 & 78 & 14.1 & $0.482 \ddagger$ \\
\hline Erectile dysfunction $(n=454)$ & 54 & 11.9 & 18 & 14.0 & 36 & 11.1 & $0.393 \ddagger$ \\
\hline Foot complication & 41 & 5.1 & 26 & 10.2 & 15 & 2.7 & $<0.001 \ddagger$ \\
\hline Otherst† & 192 & 23.8 & 71 & 27.7 & 121 & 21.9 & $0.071 \ddagger$ \\
\hline Cataract & 18 & 2.2 & 7 & 2.7 & 11 & 2.0 & $0.506 \ddagger$ \\
\hline Osteoarthritis & 17 & 2.1 & 5 & 2.0 & 12 & 2.2 & $0.839 \ddagger$ \\
\hline Spine problems $\|$ & 10 & 1.2 & 3 & 1.2 & 7 & 1.3 & $1.000 \S$ \\
\hline Gout arthritis & 46 & 5.7 & 20 & 7.8 & 26 & 4.7 & $0.077 \ddagger$ \\
\hline Malignancy & 14 & 1.7 & 4 & 1.6 & 10 & 1.8 & $1.000 \S$ \\
\hline Asthma & 20 & 2.5 & 4 & 1.6 & 16 & 2.9 & $0.255 \ddagger$ \\
\hline Renal calculi & 17 & 2.1 & 3 & 1.2 & 14 & 2.5 & $0.209 \ddagger$ \\
\hline Upper gastrointestinal tract problems ${ }^{\star *}$ & 19 & 2.4 & 9 & 3.5 & 10 & 1.8 & $0.137 \ddagger$ \\
\hline Thyroid problem $\ddagger \ddagger$ & 12 & 1.5 & 2 & 0.8 & 10 & 1.8 & $0.416 \S$ \\
\hline
\end{tabular}

${ }^{*}$ Patients may have more than one comorbidity and complication.

†Significance $\mathrm{p}<0.05$ (values in bold).

$\mp \mathrm{X}^{2}$ test.

$\S \mathrm{X}^{2}$ test with continuity correction.

ISpondylosis, degenerative spine disease or prolapsed intervertebral disc.

**Dyspepsia, gastritis, gastro-oesophageal reflux or peptic ulcer disease.

††For comorbidities and complications entered in free text.

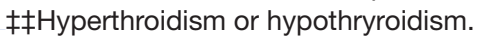

recommendations by KDIGO (2012) in which asymptomatic patients with CKD stage 3 should be screened for anaemia yearly and more often for those with CKD stage 4 and $5 .{ }^{19}$ In view of this, anaemia screening through simple FBC, which is available at every government primary care clinics in Malaysia, can be incorporated into the recommended yearly assessment of patients with diabetes but targeting to those with the significant factors found in this study. This approach could improve detection of patients who need further investigations and treatment without significant increase in the healthcare cost as the cost of FBC testing is low. Furthermore, the increased cost of an effective screening would be balanced by the reduction in the cost of treatment for the associated complications. Nevertheless, further study is still required to assess the cost effectiveness of such practice.

This was the first nationwide study in Malaysia to examine the prevalence of anaemia among patients with T2DM and CKD involving a large sample from multicentres in the public primary care setting. This 
Table 3 Median haemoglobin, prevalence of anaemia and description of anaemia according to stages of chronic kidney disease

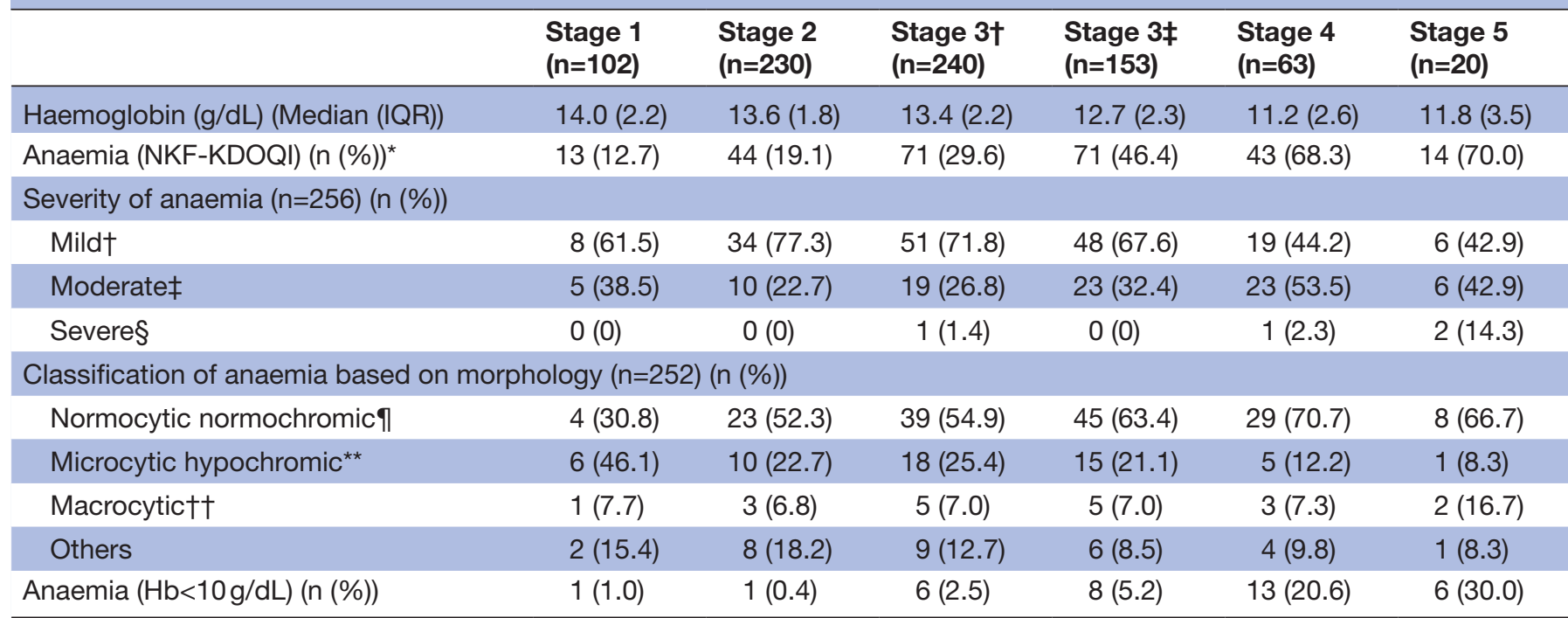

${ }^{*} \mathrm{Hb}<12 \mathrm{~g} / \mathrm{dL}$ for women and $<13 \mathrm{~g} / \mathrm{dL}$ for men.

†Mild: $\mathrm{Hb} 11.0-12.9 \mathrm{~g} / \mathrm{dL}$ for men and $\mathrm{Hb} 11.0-11.9 \mathrm{~g} / \mathrm{dL}$ for women.

$\ddagger$ Moderate: $\mathrm{Hb} 8.0-10.9 \mathrm{~g} / \mathrm{dL}$.

$\S$ Severe: $\mathrm{Hb} \leq 7.9 \mathrm{~g} / \mathrm{dL}$.

\Normocytic normochromic: Mean corpuscular volume (MCV) 80-95 fL and mean corpuscular haemoglobin (MCH) $\geq 27 \mathrm{pg}$.

${ }^{* *}$ Microcytic hypochromic: MCV $<80 \mathrm{fL}$ and $\mathrm{MCH}<27 \mathrm{pg}$.

††Macrocytic: MCV >95fL.

Hb, haemoglobin; NKF-KDOQI, National Kidney Foundation-Kidney Disease Outcomes Quality Initiative.

study was able to identify those who require the simple FBC screening to improve the care of such patients. However, there are several limitations. First, this study did not include patients with diabetes from the private primary care clinics and those in the east of Malaysia. Therefore, the representativeness and generalisability of the findings may be limited. The prevalence of anaemia among patients with T2DM and CKD at primary care settings in the whole Malaysia may also be underestimated. It is suggested that similar study could be extended by including patients from the private primary care clinics and those from the east Malaysia

Table 4 Multiple logistic regression (MLR) of the participants' characteristics with anaemia status

\begin{tabular}{|c|c|c|c|c|c|}
\hline Variables $(n=804)$ & B & Wald & Adjusted OR & $95 \% \mathrm{Cl}$ & $P$ value \\
\hline Age (years) & 0.03 & 10.34 & 1.04 & 1.01 to 1.06 & 0.001 \\
\hline Body mass index $\left(\mathrm{kg} / \mathrm{m}^{2}\right)$ & -0.05 & 6.37 & 0.95 & 0.92 to 0.99 & 0.012 \\
\hline Female (Male) & 0.45 & 6.77 & 1.57 & 1.12 to 2.21 & 0.009 \\
\hline \multicolumn{6}{|l|}{ Stages of chronic kidney disease } \\
\hline Stage $3 a$ (stage 1) & 0.90 & 6.78 & 2.47 & 1.25 to 4.87 & 0.009 \\
\hline Stage 3b (stage 1) & 1.47 & 16.56 & 4.36 & 2.14 to 8.85 & $<0.001$ \\
\hline Stage 4 (stage 1) & 2.31 & 29.07 & 10.12 & 4.36 to 23.47 & $<0.001$ \\
\hline Stage 5 (stage 1) & 2.38 & 15.65 & 10.80 & 3.32 to 35.11 & $<0.001$ \\
\hline $\begin{array}{l}\text { Presence of foot complication (no foot } \\
\text { complication) }\end{array}$ & 1.14 & 9.44 & 3.12 & 1.51 to 6.46 & 0.002 \\
\hline
\end{tabular}

MLR: Stepwise forward (likelihood ratio); 18 independent variables with $p<0.25$ in simple logistic regression were initially entered: age, gender, BMI, HbA1c, diastolic blood pressure, duration of T2DM, duration of CKD, CKD stages and presence of heart failure, ischaemic heart disease, cerebrovascular accident, hypertension, dyslipidaemia, retinopathy, foot complications, gouty arthritis, renal calculi and upper gastrointestinal (GIT) problems.

Constant: -0.289; no two-way interactions; variables were not correlated; model was fit: Hosmer and Lameshow test, $p=0.539$; overall correct percentage: 75.1\%; area under receiver operating characteristic (ROC) curve: 0.759 (95\% Cl: 0.724, 0.795; $p<0.001)$.

$\mathrm{BMI}$, body mass index; CKD, chronic kidney disease; HbA1c, haemoglobin A1c; T2DM, type 2 diabetes mellitus. 
to verify our findings. Second, this study was not able to identify the aetiology of the anaemia. The possible causes of anaemia were postulated just based on the morphology classification of anaemia, however it is inadequate as causes of anaemia are many and are not necessarily due to iron deficiency or CKD only. Lastly the cross-sectional design of the study could not determine the direction of relationship between anaemia and the associated factors. Nonetheless, our findings could provide a groundwork for future studies on anaemia among patients with T2DM and CKD in general.

\section{CONCLUSION}

Anaemia among patients with T2DM and CKD in primary care setting was common and majority was unrecognised. Most of the patients with anaemia had mild, normocytic hypochromic anaemia, but substantial proportions of those at advanced stage of CKD had moderate to severe anaemia and microcytic hypochromic anaemia. Inadequate treatment of anaemia was also prevalent. Therefore, screening of anaemia among patients with T2DM and CKD should be incorporated into the routine yearly assessment particularly for older age patients, women as well as those with CKD stage 3 and above, foot complication, lower BMI and lower DBP. It is hopeful, this will lead to early treatment and hence improve the overall care of patients with T2DM and CKD.

\section{Author affiliations}

${ }^{1}$ Klinik Kesihatan Ampangan, Jalan Seremban-Kuala Pilah, Seremban, Malaysia

${ }^{2}$ Department of Family Medicine, Faculty of Medicine, Universiti Kebangsaan Malaysia, Kuala Lumpur, Malaysia

${ }^{3}$ Department of Family Medicine, Faculty of Medicine and Health Sciences, Universiti Sains Islam Malaysia, Nilai, Malaysia

${ }^{4}$ Klinik Kesihatan Lukut, Jalan Seremban, Port Dickson, Malaysia

${ }^{5}$ Klinik Kesihatan Masjid Tanah, Masjid Tanah, Malaysia

${ }^{6}$ Klinik Kesihatan Bandar Seri Putra, Kajang, Malaysia

${ }^{7}$ Klinik Kesihatan Batu 13 1/Jalan Hulu Langat, Selangor, Malaysia

Acknowledgements The authors would like to thank the Director General of Health Malaysia for permission to publish this paper. We would also like to record this acknowledgement to the Family Medicine Specialists' Association (FMSA) of Malaysia and Roche Malaysia for their support. Special thanks to all the respective Family Medicine Specialists, medical officers and supporting staff from the participating clinics for their cooperation in the data collection process.

Contributors All authors contributed in the conception and design of the study. II, AMA, NA, NS and JHA were involved in the data acquisition. HT, NAM and MRAR analysed and interpreted the data. All authors were involved in the appraisal of the findings, the drafting of the article and the final approval of the submitted version. All authors agreed to be accountable for this work.

Funding This study was led and sponsored by the Family Medicine Specialists' Association (FMSA) of Malaysia supported by an unrestricted grant from Roche Malaysia. Veras Research Sdn Bhd was the Contract Research Organization (CRO) appointed by the FMSA to support the design and implementation of the study.

Competing interests None declared.

Patient consent for publication Not required.

Ethics approval Malaysian Medical Research and Ethics Committee (MREC) (NMRR-15-660-24324).

Provenance and peer review Not commissioned; externally peer reviewed.

Data sharing statement Data collected from this study can be obtained from the corresponding author upon the agreement from the research team.
Open access This is an open access article distributed in accordance with the Creative Commons Attribution Non Commercial (CC BY-NC 4.0) license, which permits others to distribute, remix, adapt, build upon this work non-commercially, and license their derivative works on different terms, provided the original work is properly cited, appropriate credit is given, any changes made indicated, and the use is non-commercial. See: http://creativecommons.org/licenses/by-nc/4.0/.

\section{REFERENCES}

1. Kidney Disease: Improving Global Outcomes (KDIGO) CKD Work Group. KDIGO 2012 Clinical Practice Guideline for the Evaluation and Management of Chronic Kidney Disease. Kidney Inter Supp/ 2013;3:1-150.

2. Thomas MC, Maclsaac RJ, Tsalamandris C, et al. The burden of anaemia in type 2 diabetes and the role of nephropathy: a crosssectional audit. Nephrol Dial Transplant 2004;19:1792-7.

3. Collins AJ, Couser WG, Dirks JH, et al. World Kidney Day: an idea whose time has come. Kidney Int 2006;69:781-2.

4. Al-Khoury S, Afzali B, Shah N, et al. Anaemia in diabetic patients with chronic kidney disease--prevalence and predictors. Diabetologia 2006;49:1183-9.

5. Joss N, Patel R, Paterson K, et al. Anaemia is common and predicts mortality in diabetic nephropathy. QJM 2007;100:641-7.

6. New JP, Aung T, Baker PG, et al. The high prevalence of unrecognized anaemia in patients with diabetes and chronic kidney disease: a population-based study. Diabet Med 2008;25:564-9.

7. El Minshawy O, El-Bassuoni E. Anemia and kidney dysfunction in T2DM patients. Int J Nephrol Urol 2010;2:543-52.

8. Stevens PE, Schernthaner G, Raptis S, et al. Characteristics, cardiovascular comorbidity and medicines management in patients with type 2 diabetes and CKD: results of the IRIDIEM study. Kidney Blood Press Res 2010;33:119-28.

9. Chen CX, Li YC, Chan SL, et al. Anaemia and type 2 diabetes: implications from a retrospectively studied primary care case series. Hong Kong Med J 2013;19:214-21.

10. Ito $\mathrm{H}$, Antoku S, Furusho $\mathrm{M}$, et al. The prevalence of the risk factors for atherosclerosis among type 2 diabetic patients is greater in the progressive stages of chronic kidney disease. Nephron Extra 2013;3:66-72.

11. Noor Hasimah M, Nurhanani MN, Ramli M. Medical complications among type 2 diabetes mellitus patients at a General Hospital in East Coast Malaysia. IMJ 2010;9:15-20.

12. Mastura I, Chew BH, Lee PY, et al. Control and treatment profiles of 70,889 adult type 2 diabetes mellitus patients in Malaysia - a cross sectional survey in 2009. International Journal of Collaborative Research on Internal Medicine \& Public Health 2011;3:98-113.

13. Chew BH, Mastura I, Lee PY, et al. Ethnic differences in glycaemic control and complications: the adult diabetes control and management (ADCM), Malaysia. Med J Malaysia 2011;66:244-8.

14. Feisul SI, Azmi S, National diabetes registry report, Volume 1, 20092012. Kuala Lumpur: Ministry of Health Malaysia, 2013.

15. Sazlina SG, Mastura I, Ahmad Z, et al. Control of glycemia and other cardiovascular disease risk factors in older adults with type 2 diabetes mellitus: data from the Adult Diabetes Control and Management. Geriatr Gerontol Int 2014;14:130-7.

16. Mehdi U, Toto RD. Anemia, diabetes, and chronic kidney disease. Diabetes Care 2009;32:1320-6.

17. Kengne AP, Czernichow S, Hamer M, et al. Anaemia, haemoglobin level and cause-specific mortality in people with and without diabetes. PLoS One 2012;7:e41875.

18. Mohanram A, Zhang Z, Shahinfar S, et al. Anemia and end-stage renal disease in patients with type 2 diabetes and nephropathy. Kidney Int 2004;66:1131-8.

19. Kidney Disease: Improving Global Outcomes (KDIGO) Anaemia Work Group. KDIGO clinical practice guideline for anemia in chronic kidney disease. Kidney Inter Suppl 2012;2:279-335.

20. Murphree DD, Thelen SM. Chronic kidney disease in primary care. $J$ Am Board Fam Med 2010;23:542-50.

21. Li Vecchi M, Fuiano G, Francesco M, et al. Prevalence and severity of anaemia in patients with type 2 diabetic nephropathy and different degrees of chronic renal insufficiency. Nephron ClinPract 2007;105:c62-7.

22. Jones SC, Smith D, Nag S, et al. Prevalence and nature of anaemia in a prospective, population-based sample of people with diabetes: Teesside anaemia in diabetes (TAD) study. Diabet Med 2010;27:655-9.

23. Bonakdaran $S$, Gharebaghi M, Vahedian M. Prevalence of anemia in type 2 diabetes and role of renal involvement. Saudi J Kidney Dis Transp/ 2011;22:286-90. 
24. Trevest K, Treadway H, Hawkins-van der Cingel G, et al. Prevalence and determinants of anemia in older people with diabetes attending an outpatient clinic: a cross-sectional audit. Clin Diabetes 2014;32:158-62.

25. Mafauzy M, Hussein Z, Chan SP. The status of diabetes control in Malaysia: results of DiabCare 2008. Med J Malaysia 2011;66:175-81.

26. Thambiah SC, Samsudin IN, George E, et al. Anaemia in type 2 diabetes mellitus (T2DM) patients in Hospital Putrajaya. Malaysian Journal of Medicine and Health Sciences 2015;11:49-61.

27. Dmitrieva O, de Lusignan S, Macdougall IC, et al. Association of anaemia in primary care patients with chronic kidney disease: cross sectional study of quality improvement in chronic kidney disease (QICKD) trial data. BMC Nephrol 2013;14:24.

28. Stevens PE. Anaemia, diabetes and chronic kidney disease: where are we now? J Ren Care 2012;38(Suppl 1):67-77.

29. Fucharoen $S$, Winichagoon P. Haemoglobinopathies in southeast Asia. Indian J Med Res 2011;134:498-506.

30. Thomas MC, Maclsaac RJ, Tsalamandris C, et al. Unrecognized anemia in patients with diabetes. Diabetes Care 2003;26:1164-9.

31. Loutradis C, Skodra A, Georgianos P, et al. Diabetes mellitus increases the prevalence of anemia in patients with chronic kidney disease: a nested case-control study. World J Nephrol 2016;5:358-66. 